\title{
Economical Learning
}

\section{W. Meyerhardt}

To cite this article: M. W. Meyerhardt (1906) Economical Learning, The Pedagogical Seminary, 13:2, 145-184, DOI: $10.1080 / 08919402.1906 .10532536$

To link to this article: http://dx.doi.org/10.1080/08919402.1906.10532536

曲 Published online: 30 Aug 2012.

Submit your article to this journal $\pi$

Џll Article views: 3

Q View related articles $\asymp$

4 Citing articles: 1 View citing articles 


\section{THE}

\section{PEDAGOGICAL SEMinary.}

Founded and Edited by G. Stanley Hali.

\begin{tabular}{lll}
\hline VoL. XIII. & JUNE, 1906. & No. 2. \\
\hline
\end{tabular}

\section{ECONOMICAL, LEARNING. ${ }^{1}$}

BY M. W. MEYeRHARDT.

Pedagogy in the past has been principally interested in methods of teaching. With the advent of experimental pedagogy, however, attention has shifted from the teacher to the pupil, and methods of leaming rather than of teaching are now the subject matter of inquiry.

The whole study of the conditions and methods of learning is the immediate outgrowth of memory experiments, where the measuring of memory performance, that is to say, observation under controlled conditions, affords us a more accurate insight into memory function. Such experimental study of memory has been of two kinds.

On the one hand free reproduction, not based upon definite preceding associations, has been investigated, principally by Galton, and Wundt and his students.

On the other hand, and of more immediate import for pedagogy, learning in a narrow sense is made the object of investigation, or in psychological terms, the formation of permanent associations and their effect upon retention is determined. In other words, the effect of learning is examined and measured.

Ebbinghaus (7) is generally acknowledged to be the pioneer in experimental investigations of memory work proper, of learning, and it is principally to him we are indebted for the methods employed, which, although improved in details by G. E. Müller and his assistants ( 15 and 16 ), in principle have remained practically unchanged. For a description readers are referred to their publications.

Since then a large number of experimental pedagogical in-

\footnotetext{
1The author wishes to acknowledge his indebtedness to Dr. Wm. H. Burnham for suggestions in the preparation of this paper.
} 
vestigations of this kind, or connected therewith, have been made. To be sure, the study as yet is in its infancy, which explains the hypothetical character of many of the conclusions. Much, however, has been ascertained which can safely be made use of for practical application in the school. To sift out and résumé these facts is the aim of the present paper.

\section{METHODS OF LEARNING.}

Experiment has established the fact that wherever memorizing is left to accidental success, to the uncontrolled, planless efforts of the pupil, much time and energy are wasted; that as a rule the methods employed are psychologically wrong; in a word, that children learn uneconomically.

Learning in the school has primarily for its end a single correct recitation, and after that permanent retention, or retention of the greater part of the acquired material for a certain length of time. Again, word by word reproduction may be required, or retention of general content only may be asked for. Finally, the school sometimes demands the learning and retaining of certain material for temporary use.

When we speak of economical learning, then, there is meant a method of learning which achicves its particular aim through the expenditure of the least possible amount of time and energy, and by means of a psychologically correct formation of such associations as are useful for assisting reproduction.

In order to determine just what the conditions of economical learning are, it seems necessary to inquire into the essential nature of methods of learning, and we must examine separately the factors which enter into memory work.

Given the task to memorize a poem, a vocabulary of a foreign language, a list of numbers, syllables, or words, of some length, experience shows that the first step common to most persons consists in the division of the learning material into smaller parts, each one of which is learned separately by means of repetitions, and, finally, the parts are connected by repeated reading of the whole. Few learn by always reading and repeating the whole material from beginning to end, although experimental observation shows that this latter proceeding, which we will call for short "the whole method" is psychologically more correct than the former, "the part method," and much more economical. That is, it often leads with less repetitions, in less time, to a first perfect recitation, and what is of more consequence, makes possible a more confident reproduction and more accurate and permanent retention than learning accomplished by the "part method."

In order to observe how sense material ordinarily is learned, Lottie Steffens (22), a student with Prof. G. E. Müller at 
Göttingen, made the following experiment: For twelve successive days six adults and one nine-year-old boy learned daily, the former two verses of one of Byron's poems, the latter two parts of six lines each of a German poem. All were instructed to learn each verse as quickly as possible, and to read and recite aloud until enabled to execute one errorless recitation. The observer, who had copies of the verses, designated that part which the learner read by a vertical line on the right. If he read two lines twice, two vertical lines on the right indicated that. If next be read four lines, a third vertical line of a length equal to the space occupied by four lines showed this. Thus length and succession of these lines, together with a secondary arrangement for marking lines which were read in part only, indicated the manner of learning.

It was found that all learners showed the following characteristics :

(I) Each learner divides the verse into parts.

(2) Each one repeats the parts already learned, by going back occasionally while learning later parts, either to prevent forgetting them or in order to associate the parts with each other.

(3) Fach one repeats the first lines oftener than the last ones. The boy especially used for them a quite disproportionate anount of time.

(4) Difficult parts or words are learned by means of special, separate repetitions.

(5) The end of one part and the beginning of the next are connected by means of special reciting.

(6) Adults generally learn by trying to recite that which is partially learued, controlling this by occasionally consulting the text. The boy learned by reading only.

(7) The more difficult the material, the slower is the reading.

There were individual differences, however. Some read the whole verse first, later dividing it into parts. Others at once tried to learn a part. The boy learned most erratically, wastiug as much as twenty-one repetitions upon the first two lines, while using only six for the last two, which caused irregular, hesitating recitation and superficial retention of the last part.

What are the motives, one might ask, for this common way of learning, which, as later will be seen, is so incorrect and so unpractical?

The following explanations are suggested:

(I) Attempting to learn difficult parts separately, we piece up the whole.

(2) Our natural laziness. We seem to be making better progress by learning small parts. We are diffident as to our ability to learn the whole at once. 
(3) Fsthetic feeling, irksomeness, curiosity, or interest in content, frequently counterbalance utilitarian motives.

Steffens further showed that where the same persons learned a certain number of verses of a poem by "the part method," and an equal number of the same poem by "the whole method," the employment of the latter method involved a saving of time.

While the average time required for learning a verse by "the part method" was 3 min. $3 \cdot 3$ seconds, it was for "the whole method" 2 min. 47.4 sec., a difference of I 5.9 sec. in favor of the latter.

Two learners who had shown a tendency to read the whole verse only after having several times repeated the first few lines, were instructed to learn by "the whole method." While the time for learning a verse by the old method averaged 6 min. $2.7 \mathrm{sec}$., the average for "the whole method" was $5 \mathrm{~min}$. $40.8 \mathrm{sec}$, an advantage of $19.8 \mathrm{sec}$. in the latter's favor.

Two others who had been accustomed to divide each verse into equal parts and to memorize each half separately, were induced to learn by "the whole method." Their average time for the former method was 4 min. 6 . I sec., for "the whole method" 3 min. $2.5 \mathrm{sec}$., an average gain of I min. $3.6 \mathrm{sec}$.

Experiments with children showed similar advantages in favor of "the whole method." When nonsense syllables (up to lines of 20 ) were substituted for the sense material this difference in value showed less distinct, but still quite noticeably in favor of "the whole method."

The following considerations may serve for partially explaining this astonishing advantage of learning a material "as a whole" over that of learning it by parts:

(I) In learning by "the part method" the connections between the various parts must be learned separately, work, which in learning by "the whole method," is eliminated.

(2) In learning by "the part method" we associate the end of each part with its own beginning instead of with that of the next following section. These wrong associations later on disturb recitation and therefore must be artificially repressed; that is to say, they must be unlearned by memorizing with special care the transitions to succeeding parts, whereby correct associations are formed.

(3) In learning a material, not only the immediately following parts are associated, but more distant parts also aid each other by so-called mediate association, and again, we fix certain parts more firmly by localizing them, by noting their particular position in the whole. In learning by "the whole method" all these aids are utilized with each reading, while in learning by "the part method"' the opportunity for taking advantage of them is almost entirely lost. 
(4) In learning by "the whole method" all parts are more uniformly associated; for we are saved from devoting too many or too few repetitions upon respectively easy or particularly difficult passages or parts.

Not quite so pronounced advantages in favor of "the whole method" are shown in experiments by P. Ephrussi (9) at Göttingen, which were conducted, however, upon a somewhat different plan.

In the school as well as in life it is often necessary to memorize material the components of which must be associated by pairs. In learning the vocabulary of a foreign language, for instance, where the foreign words are to be associated with the corresponding ones of the mother tongue, or when the names of cities with their respective number of inhabitants, or historical events with the dates of their occurrence are to be memorized, - in all such cases two methods of learning are possible. The material can be learned as a whole, that is to say by reading and rereading the vocabulary, data, etc., always from beginning to end, or one can proceed to read and repeat each single pair until committed to memory, before taking up the next pair. This may be called learning by the "cumulative method" and would correspond to what previously has been called learning by "the part method."

Here again the question arises, by which method do we more quickly, with a smaller number of repetitions, attain our purpose, which in this instance, however, is not a perfect recitation, but retention of the associated pairs. In other words, given one of the two components to be associated, the other must be named.

Like Steffens, Ephrussi took "time required" for his scale of measurement, principally, perhaps, because it is best adapted to quantitative determination.

Twenty-four persons, consisting of is gentlemen and 6 ladies, all university students, and 3 girls I 3 , I 5 and 16 years old, of a more or less perfect common school education, participated in his experiments, which extended over from 8 to 36 days, one hour daily being used.

As a first experiment 25 pairs of nonsense syllables were learned, as much as possible without secondary memory aids, that is by what is commonly called mere mechanical memorizing. This experiment furnished the following conclusion:

"With normal concentration of attention "the cumulative method" is more advantageous. When attention is defective, however, "the cumulative method" loses its advantage and sometimes even is inferior to "the whole method."

In another experiment word pairs of Russian-German vocabulary, which one may call sense-creating material, were mem- 
orized. Among the subjects were two young girls who never before had studied a foreign language. Here again "the part method" with its cumulative repetitions gave better results than."the whole method," although its advantage was less apparent than where nonsense material was used.

In a third experiment, on the other hand, where a mixed material was used, each pair being composed of a German word of two syllables and a number of three figures, learning by "the whole method" proved a decided advantage.

These discrepancies, according to Ephrussi, are to be explained as follows:

The learning process embraces two psychic processes, (I) familiarizing oneself with each part of the material, and (2) association of the parts. Formation of associations between the parts of the memory material begins in reality only when the material is a familiar one, or has reached a certain degree of familiarity. That particular method, then, is apt to prove more expedient, which produces this familiarity with the smallest number of repetitions. Wherever, on the other hand, the material is to begin with a familiar one, the economic value of a method is apt to be determined by factors which in unfamiliar material play more of a secondary part, for instance, by the degree of stimulation of attention through the manner of presenting the material.

For the advantage of "the cumulative method" in learning a vocabulary he advances the reason that in learning by that method, where each pair is repeated say 5 times, the second component of each pair besides being read 5 times after the first, at the same time is read 4 times before the first, thus establishing firmer association between the pairs than in learning by "the whole method," where this advantage is lost.

One might here remark that the same ought to hold true for learning a combination material, and perhaps even to a greater degree, because both components of the pair are of the familiar kind. As borne out by his experiments, however, this is not the case, "the whole method" showing here a decided advantage. We must suppose, then, that other factors enter which have a bearing on this question. The discussion of these, however, must be for the present deferred.

In the meantime we may summarize the conclusions drawn from Ephrussi's experiments as follows :

(I) The more familiar the material, the easier is association.

(2) In learning by pairs two kinds of association must be considered (a) association of the first with the second part, (b) the reverse, which leads, when the second part is given, to a reproduction of the first.

(3) Of two otherwise equivalent methods that one is more 
expedient which with less repetitions leads to a greater degree of familiarity.

(4) In learning unfamiliar material "the part method," with its cumulative repetition of the pairs, seems preferable, provided, bowever, that the repetitions for each pair are not so numerous as to cause an involuntary relaxation of attention.

(5) In learning waterial which is familiar, "the whole method" gives better results.

In Steffens' and Ephrussi's experiments, it will be noticed, it was the time required for learning which determined the economical value of a method. Expenditure of energy and permanency and accuracy of retention were not considered. It is obvious, however, that these must be reckoned as factors which play' an equal, if not more important, part in economy of learning. Our analysis, therefore, would be incomplete unless we reviewed experiments by Professor Meumann and his assistants at Zurich ( $8,13,19)$, whose investigations are perhaps the most comprehensive of all. Professor Meumann set himself the task to answer by experiment the following questions :

(I) By which method do we attain more quickly, with fewer repetitions, a first perfect reproduction?

(2) Which method is most conducive to a uniform distribution of attention upon the memory material and to the formation of correct associations?

(3) Which method leads to more confident reproduction and to more accurate and permanent retention?

In one experiment five school children, 2 girls and 3 boys, $8,10, I 1,12$ and 14 years old took part. The question to be answered was: "Is it more economical to divide a material into few or numerous parts?"' For instance in learning a poem of 4 verses, is it more expedient to learn each verse as a whole or to divide it into smaller parts? The experiment proved that the greater the number of parts into which the material is divided, the less economical is the method of learning. The nearer we approach learning by "the whole method," the quicker and better we succeed. Experiments with adults further showed that the more voluminous the material the greater is the advantage of learning by "the whole method." In learning nonsense material, however, this does not manifest itself as clearly as where sense material is memorized. It is here that the differerence in value of the two methods becomes more discernible. Let me quote a few examples. Miss $K$. learned each day for Io days 2 verses of Schiller's Dido, using on the Ist, 3 d, $5^{\text {th }}$, 7th and 9 th day "the part method," on the remaining days "the whole method."

It was found that on an average the verses were learned by "the whole method" with a saving of 14.5 minutes, which in 
view of the size of the material, 2 verses of a poem, is considerable. Moreover, as later experiments proved. the verses learned by "the whole method" were longer retained and were recited with more confidence. As to repetitions, the highest number for learning 2 verses by "the part method" was 33 , while in learning "by the whole method" never more than $14, i$. $e$. less than one-half were required.

Finally, it was also ascertained that verses originally learned by "the whole method" required less time for relearuing than all others.

The material for another subject, Mr. K., was more voluminous. He learned 5 verses of' 8 lines each by "the part method" and an equal material by "the whole method." For the first he required 45 repetitions, for the second only $\mathbf{2} 2$, but the time used for learning was in both cases approximately the same: about 32 minutes.

It would seem, then, that the advantage of learning by "the whole method" does not always rest, as Steffens showed, in the saving of time, but chiefly rather in the smaller number of repetitions, the psychologically more correct formation of associations, and better retention. The gain of time, it was found, was not so pronounced, because most subjects, when learning by "the whole method," instinctively read slower than when piecing up the material. They read with more stress, and difficult passages especially were read slowly and with highest possible concentration of attention.

Let us here stop an instant in order to compare the two methods in regard to the psychic processes which come into play, more particularly in regard to attention and the formation of associations.

(1) In learning by "the whole method" firmuess of association between the single parts is more even, because the repetitions have been more uniformly distributed.

(2) Associations have been formed in that directicn only in which they will aid future reproduction.

(3) Association of the parts with reference to their particular position in the whole has been primarily correctly formed, and is with each reading reinforced, a fact which aids reproduction.

(4) In sense material, content and logical connection aid the formation of associations more effectively when learning is by "the whole method."

On the one hand the content of the whole is easier apprehended when read as a whole, on the other, the content of each part also becomes clearer when apprehended as a part of the whole.

Now the aid which content affords in learning is often so great as to counterbalance $9 / 10$ of the efforts of mechanical 
learning. By piecing up the material, therefore, we disturb the efficacy of one of the most powerful levers of memory.

(5) In learning by "the whole method," attention is riveted upon the content, and remains in more uniform tension, thus preventing mechanical learning and mere motor recitation, which are useless for memory. It is this fact mainly which explains the need of fewer repetitions, each one being utilized to the fullest extent.

In our previous discussions all conclusions were based, almost exclusively, upon the results of experiments with adults. Our particular task, however, is to determine whether these differences in the value of methods of learning hold likewise for the memory of the child.

Not to anticipate, it may suffice for the present to state that not in all points is this the case. Nor is it on consideration to be expected. Experiment has demonstrated that the general opinion, shared by pedagogues and psychologists alike, that the memory of children, and more especially the mechanical memory, is superior to that of adults, is erroneous.

Bolton (3), by his experiments with school children under I4, proved that the development of their memory depended upon age rather than general intelligence. That is to say, at a given age, even the most intelligent child's memory capacity is confined within certain definite limits, and that of older pupils is on the average greater, purely by virtte of their age.

This alone would justify the assumption that adults should exhibit greater memory capacity than children up to 14 years of age.

Alexander Netschajeff, of the University of St. Petersburg ( I7), made similar extensive experiments for the purpose of observing the development of memory in school children.

687 pupils from 9 to 18 years of age were examined by classes. Having been given a series of 12 sense impressions, they were supposed to write down regardless of succession as many as they could remember.

(I) They were silently shown 12 objects: newspaper, key, book, etc.

(2) They heard 12 inarticulate sounds: knocking on wood, tearing of silk, etc.

(3) I 2 numbers over ro and below roo were read.

(4) Twelve words of 3 syllables expressing visual conceptions were read: wagon, in Russian Kolaska; lead pencil, Karandâsch; scissors, nóschnizi, etc.

(5) 12 words of 3 syllables calling up auditory concepts were read : $y$ tschanje to grunt, mytschanje to roar, etc.

(6) I 2 words were read expressing temperature and touch sensations. 
(7) I 2 words were read suggesting affective states.

(8) I2 abstract terms like déjstwie effect, prosstranstwo space, etc., were read.

Although the principal aim of these experiments was to determine the influence of the meaning of words upon retention with particular reference to the differences between boys and girls, we can also make use of his figures for our present purpose.

They show: (I) A steady growth of memory capacity with age, except during the period of puberty, when it is somewhat arrested.

(2) The meaning of words exerts a great influence upon retention.

(3) The memory for numbers showed the smallest relative growth.

While, for instance, the average number of objects remembered by 9-year-old pupils was 6.4, that of 18-year-old pupils was 9.7 , a difference of $3 \cdot 3$.

The average retention of words denoting an affective state, was for 9-year-olds 3 , for I 8-year-olds 6.3, a difference of 3.3 .

On the other hand, the average of numbers remembered was 4.4 for 9-year-old pupils, for 18-year-olds 5.3, a difference of only 0.9 .

While in general, then, I8-year-old pupils are superior, in remembering numbers, which involves mere mechanical memory, the 9-year-olds apparently are nearly, if not quite, their equals.

Cowmon observation also shows that adults experience often great difficulties in mechanical memorizing, while children accomplish the same with comparative ease. Nevertheless, let that not deceive any one ; for it does not prove what it seems to. We know that all our faculties are dependent upon continuous exercise. Now it is the fact that adults are accustomed almost exclusively to sensible memorizing, to retention of the general content, which is apt to account for their inferior mechanical memory performances, not the loss of that faculty. Adults, as experiments by Professor Meumann show, can enhance their capacity so as to learn 3 or 4 times as much as a child in any given time. He found that in learning lines of from 16 to 24 nousense syllables, adults after brief practice became greatly superior to children under 14 years of age. Younger children are handicapped by the fact that they become easily fatigued. It is utterly beyond the capacity of 8-year-old children, Professor Meumann observed, to learn a line of 16 syllables during one session, even when reading till exhausted, while adults learn lines of 24 syllables without noticeable fatigue. Moreover, it is not only lack of exercise which impairs the mechanical memory of adults, but the direction of in- 
terest and attention which are focused habitually upon the content. When obliged, therefore, to memorize mechanically, they find it difficult to readjust attention.

Professor Meumann holds that it is the small capacity of childmemory which partially explains the results of experiments with various methods of learning. It was found that in mechanical memorizing, children, to begin with, succeed better when learning by "the part method." This grows out of the fact that learning by "the whole method" at first renders them ill-humored and discouraged, because they seem to be making no visible progress. Experience, however, shows that in the mental work of children, particularly of younger ones, their disposition, their mood, is of great consequence. This is not conquered, as in the case of adults, by increased effort, but they easily succumb to the paralyzing influence of depressing emotional states. The old adage "nothing succeeds like success" truly holds here if any where; for the knowledge of being able to master a problem is a powerful stimulant and important factor in their work. Hence their apparent success when learning by "the part method." But this is quickly changed when, convinced of their error, their sceptical attitude is once abandoned. Then, with but little practice, it was found, children, like adults, learn quicker, with less repetitions and better retention when learning by "the whole method."

A boy 8 years old, for instance, learned verses of Goethe's Erlkönig by "the part method" with I 7 repetitions, by "the whole method" with Ir. Another verse, divided into two parts, required 5 repetitions; the next, learned as a whole, only 10. About the same ratio obtained in all experiments with school children.

In learning material which forms an unconnected whole, like a vocabulary, dates and the like, Meumann's experiments show likewise that it is of greater advantage to learn by "the whole method." Vocabularies were learned up to 50 word pairs (German, with its corresponding Italian, Russian, Latin or Bulgarian word), alternating in the use of "the whole method" and "the cumulative method." In each case and in every respect, he assures us, the former method proved the more economical. Uniform distribution of repetitions and more even concentration of attention account for this. Attention finds with every step something new; this prevents mere motor recitation towards which children especially incline when learning by "the cumulative method."

These results it will be noticed are at variance with those described by Ephrussi. It must, however, be borne in mind that he only measured the time required for learuing, which is but a minor factor in determining the value of a method. 
Furthermore, his subjects were extremely sceptical as to their ability to learn by such an unfamiliar method, an attitude which tends greatly to impair success. Finally, in learning a vocabulary, mere mechanical memorizing is involved, to which adults, as a rule, have become unaccustomed. (A former school superintendent of this city reports that pupils of the $7^{\text {th }}$ and 8th grades show greater aptitude for studying German and French than older ones, whose capacity for mechanical memorizing from lack of practice obviously has grown less.) Again, the relative inability of children to concentrate attention is a well-known fact, and it does not seem safe to assume that what holds good for adults will also prove true of the child.

While experiments thus seem to make certain that generally speaking the method of learning "as a whole" is the better, it has nevertheless, as might be easily inferred, its disadvantages. In actual work, one condition of all experiments, namely, homogeneous material presenting equal difficulties throughout is rarely found. Hence, where some parts are especially difficult, all others, although already learned, must be repeated for their sake.

Again, concentration of attention in learning, say a verse of 8 lines, or a line of 16 syllables, is not as uniform as is ordinarily supposed. It rather forms a typical curve, which shows at the beginning and end a relative maximum, in the centre or just beyond a minimum of attention. As a consequence, the middle section is learned last, and is soon entirely forgotten when the whole has not been thoroughly learned.

In learning lines of 16 syllables, for instance, the first and last few are usually remembered first, the gth or I oth last. Where the line of syllables is very long, two such depressions in the attention curve are apt to appear. In learning by "the part method" these do not occur, because here with each part attention sets in again with a maximum of concentration.

It must be obrious, then, that for practical application the value of "the whole method" might be enhanced and its disadvantages avoided by certain modifications. Meumann proposes two such modified methods which, because they combine the respective advantages of both "the whole" and "the part" methods, while eliminating their disadvantages, he chooses to call "mediating methods." The following was found useful for all kinds of memory material: The whole material to be memorized was, with special regard to parts presenting unusual difficulties, divided into several sections, which were marked for the eye by means of a line, or wherever possible by an intervening empty space. In attempting to learn the material, a brief pause was made after each section, but the learner did not, as in learning by "the part method," return to the beginning of that section, but kept on reading to the end. In this 
way he memorized by "the whole method" and profited by all its aids, while, on the other hand, the pauses between the sections caused attention to set in again with a maximum of concentration.

Let me give an example: I 2 syllables are divided into two groups of 6 each, with a space between them, and while learning them "as a whole" a small pause is inserted between groups. In learning a verse of 8 lines one can proceed similarly, with the difference that here a line is the unit.

A second method, which is employed best in memorizing a vocabulary, consists in learning by "the whole method" until certain word-pairs are found which offer greater difficulties than the average. These are marked off and practiced separately, after which one returus to reciting the material "as a whole" until it is uniformly remembered.

Ebert and Meumann (8), in an extended series of experiments, had occasion to compare the relative value of various methods of learning.

The material consisted for series No. I of 8 groups, each one of which was composed of 4 lines of 12 syllables each; for series No. II, of 4 groups of 4 lines of 12 syllables each. For series No. III the material was made up in a manner which corresponded to series No. I.

Four methods were compared :

(I) "The whole method," where each line was learned as a whole.

(2) "The part method," where each line was divided into two equal parts, each one of which was learned by itself, before the line was read as a whole.

(3) "Mediating method No. I," called for short "the $2 \times 6$ method," where the line was learned as a whole, with a pause equal to the time value of one syllable inserted after the sixth syllable.

(4) "Mediating method No. II," or "the $3 \mathrm{x}_{4}$ method," where two such pauses were inserted, after the fourth and eighth syllables respectively.

Each group consisting of 4 lines, a different method was employed for learning each line, so that in each group all four methods were tried, whereby the mediating methods were used alternately at the beginning and the end of a group.

The following chart shows for each of the six subjects, and for each of the four methods, under $a$ "the average number of repetitions required for learning a single line," under $b$ "the average number of repetitions for relearning a line after 24 hours," under $c$ "the average percentage of saving in repetitions, when relearning." Under $A$ is given the total average of all subjects for $a, b$ and $c$ respectively. In series No. III only 3 subjects participated. 


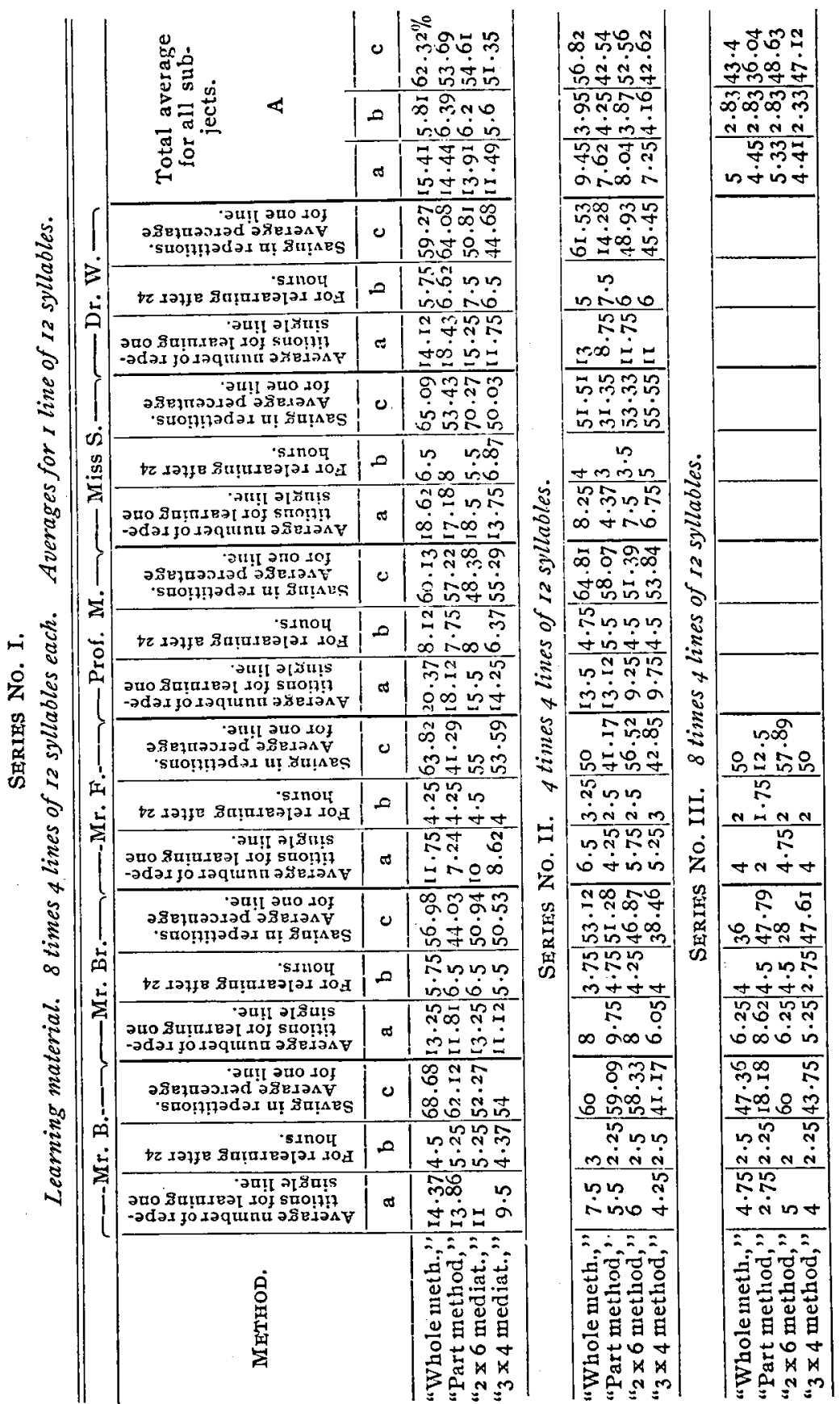


In series No. I it will be seen, that objectively regarded, it is "mediating method II," or "the 3x4 method," which showed itself most advantageous, the average number of repetitions for learning as well as for relearning being smaller than elsewhere. On the other hand, "the whole method" shows by far the greatest average percentage of saving in relearning. Here, evidently, associations have been more firmly established by the originally greater number of repetitions.

In series No. II the medium average of all four methods combined for learning a single line is 8.09 , which again proves the superiority of "mediating method $3 \times 4$." The medium average for relearning is 4.05 , and the medium average of saving $48.63 \%$.

It is obvious then that, other things being equal, those methods which originally require a greater number of repetitions are the ones which require fewest for relearning. This result is in accord with the fact experimentally established by Otto Lipmann (12): "that a new repetition is of greater value for such associations which at a given previous time were more firmly established."

In series No. III the medium average for learning is 4.79 repetitions, and again it is "the $3 \times 4$ method," which surpasses this more than any other. The medium average for relearning is 2.70 , which proves that with practice "the $3 \times 4$ method" also gives the best results in relearning. Evidently, however, the all around greater skill in mechanical learning, which has been acquired by long continued practice, has a tendency to render the average number of repetitions required so nearly alike, that it does not seem to matter much by what method a line of syllables was originally learned.

\section{SUMmaRY.}

We can now summarize these experiments on methods as follows:

(I) Each one of the old methods has its characteristic stroug and weak points.

(a) The weakness of "the part method" consists in the formation of irrelevant associations, its advantage, in the setting in of attention with full vigor and energy at the beginning of each part.

(b) The weakness of "the whole method" consists in the relaxation of attention, so that the middle part of the material is not so thoroughly learned as the beginning and the end. Its advantage is to be sought for in the formation of associations in that direction only in which they shall be effective in reproduction. Again, it prevents mere motor recitation, which for the process of learning remains relatively or entirely ineffective.

(2) The "mediating" methods combine the advantages of 
the "whole" and the "part" methods and avoid their respective disadvantages.

(3) The question "which method of learning is more economical" can be answered from two points of view. A method may be advantageous because it leads quicker to a first errorless recitation,- - or, because it effects more accurate and permanent retention and more confident reproduction.

From the first point of view our " $3 \mathbf{4} 4$ mediating method," where the material is learned as a whole but with two inserted pauses, is the best.

From the second point of view the best method is "the whole method."

(4) "The part method," as far as rapid learning is concerned, stands closer to the "mediating" methods than to "the whole method."

(5) The effect of the methods of learning upon memory work varies in several respects:

(a) The "mediating" methods are conducive to rapid learning aud to retention of medium permanency and reliability.

(b) "The part method" effects relatively rapid learning but retention is neither reliable nor does it persist for any great length of time.

(c) "The whole method" requires often more time and repetitions for first learning, but leads to greatest accuracy and permaneucy of retention and to more confident reproduction.

(6) With long continued exercise in mechanical learning the psychic effects of the various methods approach each other, the learner evidently becoming more and more adept in eliminating the inexpediencies of one method or the other, and in utilizing its advantages.

\section{INDIVIDUAL DIFFERENCES.}

Earlier psychology regarded what Bacon calls "the negative instances" simply as deviations from the average, and often even as errors. With us, however, the most interesting, and frequently the most instructive thing in psychological experiments, is the observation of individual differences. Here an opportunity may present itself to reduce individual abilities to their elementary psychological conditions, and thereby bring us one step nearer to the solution of the problem of human individuality.

In connection with experiments on memorizing, among the many, two fundamental individual differences seem most important, - the difference in the rate of learning, and the difference in the accuracy and permanency of retention.

Experiments show that the difference in the rate of learning is radical, and determines entirely differentiated memory types. 
The rapid learner is distinguished not only by the quickness with which he accomplishes his task, that is, arrives at a first errorless recitation, but his whole manner of learning, the effect of learning on retention, his way of relearning, intensity and adaptation of attention, and the course of gradual forgetting differ from that of the slow learner. In a word, each one of these two represents a peculiar memory type, possessing characteristics which are demonstrable in experiments.

The first characteristic, of course, which marks the rapid learner is the fact that he requires less time and fewer repetitions for the production of a first errorless recitation.

For example: Mr. Z. learned a line of 12 syllables with an average of 56 repetitions. Mr. P., who is of approximately equal age, required only I8. After four weeks' practice in learning lines of nonsense syllables $Z$. required 25 repetitions for learning a line, P only 6 .

In learning sense material the types approach each other, because here interest in and special ability for certain material exert an influence; still they remain entirely distinct. In children of approximately equal age similar differences were found. The amount of time expended in learning is naturally proportionate to the number of repetitions required.

On the other hand, the rapid learner also forgets more quickly. With him one errorless recitation does not insure retention for any great length of time. His whole way of learning tends towards temporary rather than permanent retention. In reproducing he recites restlessly and more rapidly than when learning. By means of the after images of sense impressions he effects mere immediate retention, which lasts only as long as the direct after effects of the sense impressions, and disappears with them. As a consequence, while reproducing, he is always alert to make use of anything in his earlier learning which might assist memory, such as pitch, tempo, rhythm, and the like. Just as soon as he feels certain of having learned the material, he is anxious to recite at once, which in fact is necessary, for in some instances it was found that two minutes after learning a line it could no longer be reproduced, and that, after five minutes, forgetting had so far progressed that the learner was no longer able to recognize syllables as having occurred in a line which had been learned. Thus the typically rapid learner as a rule proves likewise the rapid forgetter.

Quite different is the behavior of the slow learner. He requires more time and repetitions for learning, and is not at all anxious to recite at once, but, on the contrary, often asks for some little time, presumably in order to coordinate that which has been learned. He reproduces with great confidence, recites 
slower than when learning, and after some minutes still reproduces equally well.

Many other qualities distinguish the two types. The rapid learner is unable to recollect a syllable, when once it has been forgotten, while the slow learner, by forcing memory, usually recovers the missing syllable. The rapid learner depends a great deal upon the first syllable of a line, and in forgetting that, he forgets the whole line. The slow learner is able to begin in the centre, and to reconstruct the line backward and forward. The slow learner abides for a long time by the reading of the material, while the rapid learner soon attempts recitations, controlling these by occasionally consulting the text. The attention of the rapid learner is easily diverted by trifles, which the other does not notice at all. The rapid learner is all excitement, imbued with the one idea to achieve his aim as quickly as possible. The slow learner feels worried only about his ability to succeed without the expenditure of too great an amount of time.

Again the relative gain by practice with the slow learner is usually much greater than with the rapid learner. The above mentioned Mr. Z., during a long continued series of experiments, required at first 56 repetitions for learning a line of syllables, after some months' practice only I9, a gain of about 66 per cent. Mr. P. learned at first with I 8 repetitions, later with 8 , a gain of less than 56 per cent.

Nevertheless, while the rapid learner, when free reproduction is in question, seems to forget more quickly, it must not be assumed that he is also at a disadvantage when relearining is demanded. Here he is able to utilize most fully the least remaining traces of his former efforts, and therefore shows quite often a greater saving in repetitions.

Finally, in regard to immediate memory, the rapid learner makes a better showing than the slower one. The greatest number of syllables $P$. could repeat after hearing them once was $8, Z$. only 3. A child of the rapid learning ty pe managed to remember 6 syllables, another pupil of the same age only 3 .

If asked to explain the causes for these differences in types of learning, we are forced to confess that nothing definite is known. Physical condition seems to have a bearing on the phenomenon. Alexander Netschajeff ( 17 ), who examined I 30 school children with spirometer and dynamometer, found that of pupils of the same age the stronger ones, on an average, had also the better memory. Practice in learning and general intelligence possibly play a part. As to the principal cause, however, as Meumann points out (13), it must probably be looked for in the fundamental differences of attention in the two types. "It is chiefly the difference in the rate of central 
adaptation to the present activity which conditions the different effects of learning," he declares. The rapid learner is able to adjust his attention almost immediately to the particular demands of whatever activities he may be engaged in, and thus he attains quickly his maximal concentration, with the result that his first few repetitions have full value for memory, and no part of his efforts is lost. The learner whose adaptation is slow, on the other hand, reaches his maximum of concentration only gradually, and his first few repetitions are of little value for the purpose of retention. True enough, the rapid learner also loses adaptation more quickly, but that is not of much consequence; for he is able to regain it almost at will. This is seen plainly in the effect of pauses during the act of learning. While short rests are agreeable to both types, long intervals the slow learner avoids from fear of loss of adaptation.

Thus both qualities, rapid and slow adaptation, have their advantages as well as their disadvantages. While one of the former type can readily change from one activity to another, a feat quite difficult for the other, the latter, after not too great pauses, is able to continue his work with uniform energy and concentration, because during the interruption he has not lost his adaptation.

Again, connected in many respects with the learning types, are the so-called image types. As is well known, Charcot, in psychopathological clinics, observed that we think in images, which are the result of impressions by the various organs of sense, and we now distinguish between the predominately visual, auditory, or motor types. As might be expected, the manuer of learning is conditioned by, and correlated with, the manner of imaging. The visualizer learns by means of his images of word groups and arrangement of syllables. The auditory and motor types in reading immediately transform the visual into auditory or motor images. Their mode of learning consists in the formation of a number of successive images of sounds or spoken words, or of successive innervations of speechmuscles, accompanied by corresponding movement sensations. As a consequence, in reproduction, they are obliged to run off a line of syllables, either in thought or in words, while with the visualizer retention is simultaneous association. He is able to reproduce a line equally well either forward or backward, a rather difficult task for the other types, whose association is successive.

Unfortunately, the accuracy of retention of the various image types has not been investigated. It would seem, however, that visual memory, while working slower, is the more accurate, and that as a rule it is the visual learner who in reproduction displays a greater degree of certainty. 
Finzi (ro), in the course of his experiments, found that visual impressions are less subject to falsification than auditory impressions. Müller and Schumann (I5) and Müller and Pilzecker (16) made similar observations. Meumann reports (13) that mental calculating is done slower but with far less errors when visual imaging supplements the acoustic-motor images of numbers.

Müusterberg and Bigham ( $44 a$ ), in experiments with numbers and colors, found that with their subjects the average of errors committed by visual memory was about $\frac{1}{5}$, to be exact 20.5 per cent, while that of auditory memory was about $1 / 3$, or more exactly 31.6 per cent. They further ascertained that when visual and auditory memory come into play simultaneously, the number of errors diminishes considerably. Thus with a subject, whose memory for numbers in the auditory series showed 14. I per cent. of errors, and in the visual series I0. 5 per cent., the percentage of errors descended to 3.9 per cent., when the numbers were at the same time seen and heard.

In all probability, then, one would not be wrong in saying that the two elementary qualifications which characterize the slow learner are slow adaptation of attention and visualizing. A perfect memory, accordingly, must be supposed to be founded on all around developed imaging. If true, this is a pedagogically important fact to which we shall have occasion to refer again.

Further individual differences are revealed by the manner in which various individuals effect primary or immediate retention. Here again typical differences in the whole conduct of learners are found, as well in regard to the behavior of attention as to the memory aids by which primary impressions are retained. To show these most clearly I can do no better than compare the conduct of two of Meumann's subjects named Mr. D. and Mr. F.

The first divergence we find in the nature of their errors when reproducing letters and numbers. F. mostly makes mistakes of position. D. mistakes of sound. That is to say, the former misplaces letters or numbers in a line, while the latter substitutes for certain letters others of similar sound. When the letters or numbers are read, D.'s memory is aided by closer print, a factor which is of no consequence for $F$. When made to listen with their tongue clasped between the teeth, $F$. makes more mistakes than $\mathrm{D}$.; the former also is actuated by a strong impulse to draw back the tongue. It would seem, then, that $D$. obviously retains, by means of acoustic images, $F$. by means of imaged or actual speech movements.

The chief difference, however, is that of attention. D. directs attention not upon the single letters, nor does he actually 
focus the whole line, but he diverts attention so as to take in the whole uniformly, with a mere flash of consciousuess. "Immediately after speaking has ceased," he declared, "I have only a weak acoustic total image of what I have heard, which rapidly becomes more distinct, and I then write quickly as a whole what I retain." F. describes the behavior of attention as just the reverse. "I direct attention," he says, "upon each single letter, and in writing I connect successively the single parts, giving each its place in the line."

F.'s attention, therefore, is discrete, that is to say, it is directed successively upon the single parts, each one of which is added to the others until the whole is formed. D.'s attention is a kind of total attention, which in reality begins its full work only after the whole line has been spoken. D.'s attention works analytically, F.'s synthetically.

Here, then, it would seem, we have to do with an inner connection between the memory aids of these two individuals and the behavior of their attention. It is F.'s motor way of retaining, making it necessary for him to accompany each letter with separate speech innervations, which directs his attention upon each single part of the line, while for D.'s acoustic way it is of greater advantage first to allow the single parts to melt into "a whole," in order to reproduce only that. We are justified in this assumption by the well-known behavior of attention in other mental activities, in reading, for instance, where some focus the single parts of a word, others as large a reading field as possible. We speak there of fixating or fluctuating attention.

When we approach the field of learning aided by content, conditions become more complicated as the result of a vast number of possibilities which grow out of the nature of the sense material and its effect upon the learner. The material may be on the one hand of a more perceptive or a more notional character, on the other, it may be logically more or less abstract. Agáin, its meaning may be simple and clear, or complicated and obscure. Grammatical construction, length of periods, alliteration, rhythm, and many similar factors are of consequence for memory. In view of the many problems growing out of these conditions, the facts which so far have been ascertained seem rather insignificant, still they are pedagogically important.

Experiments here again have brought to light the existence of typical individual differences in rational memorizing. One class of learners pays attention almost exclusively to content and logical connection, and remembers the words only in regard to the way in which they give expression to these.

In learning a poem, for instance, they depend upon as clear 
as possible a realization of the events, actions, persons or localities described. In learning prose, content is a still greater factor, while in addition grammatical connection of periods is noticed. Rhythm, rhyme, length of words and periods assume the character of mere secondary memory aids. With others, however, the sensory elements of the material play the priucipal rôle. They observe in the first place the optic elements, length of words and periods and their location in the material. Or else the acoustic elements, like pitch and rhythw of their own voice, alliteration, phonetic difficulties, and the succession of motor innervations in speaking. Here content is of secondary importance.

A third typical difference consists in the fact that some learners attempt to fix the whole material "as a whole." In learning a poem, for instance, the single lines or periods are learned only as parts of the verse, the single verses only as parts of the poem, and attention is focused upon this total connection of the content. Others, on the contrary, arrange the single parts contiguously and then join them to the whole. Their attention is synthetic, that of the former analytic.

As a fourth variety, although not of fundamental import, may be mentioned what Ephrussi (9) styles the "ingenious type." They show a tendency to learn by the aid of all possible secondary, self-constructed ancillary associations, which others dispense with altogether. A majority of these secondary resources, however, disappear in the course of a long continued series of experiments, especially when the learner makes an effort to avoid them; and they are the result of habit rather, it would seem, than of differences in memory organization.

A comparison between the memory performance of school children and that of adults indicates that the inmediate memory of the former is much inferior. If we array the restults of experiments with school children by Binet and Henri (2) against those with adults by Professor Meumann (8), we find that the accomplishments of children from to to $x$ years old average about $1 / 3$ or $1 / 4$ of those of the skilled adult. While adults sometimes remember I 3 or I 4 letters or numbers, 8 or 9 syllables, 12 words, 24 words of a verse, and as much as 36 words in prose, pupils $I$ and 12 years old rarely are able to reproduce correctly more than from 3 to 5 impressions.

Practice, of course, may have enhanced the ability of these adults to a point beyond the average, and again the individual performances of children of equal age often differ greatly. Some of the more gifted retain nearly twice as much as others. On the whole, however, there is hardly room for doubt that the primary memory of the average pupil is little developed, which 
reminds one that the old school maxim that "questions by the teacher should be brief," is psychologically well fouuded.

\section{SFCONDARY CONDITIONS OF LEARNING.}

According to Ebbinghaus ( 7 ), the manner in which repetitions are distributed is of great consequence for economy of learning. He found that by distributing the repetitions over a more extended period of time, it is possible to learn lines of nonsense syllables with a smaller number of repetitions. While, for instance, the learning of a line of 12 syllables required 68 repetitions, which immediately followed one another, 38 repetitions distributed over three days produced the same effect.

In agreement herewith stand the results of investigations by Ad. Jost ( I I), a student with G. E. Müller, who found that associations are stronger when formed by repetitions distributed, with 24 hour intervals, over several days. A line of syllables, for example, learned with 30 cumulative repetitions, was not as well retained as a similar line which had been learned by repeating it ro times each day for three successive days.

Jost further found that the more extended this distribution of repetitions, that is to say, the longer the period of time over which they are distributed the greater is the advantage for learning. He therefore formulates the law that "where two associations are of equal strength but of different age, a new repetition is of greater value for the older of the two." Experiments by Müller and Pilzecker (16) and Otto Lipmann (12), on the whole, have verified his results.

The significance of Jost's law is apt to become most apparent in learning voluminous material, where by distributing the repetitions we work in part with relatively older associations, while in forcing learning by cumulative repetitions all associations are relatively alike new.

Ebbinghaus ( 7 ) adroitly points out that the instinctive behavior of teacher and pupil have foreshadowed the findings of experiment. "The pupil," he writes, "in learning a vocabulary or rules, does not usually force memory by trying to learn them at once in the evening; he knows that it is necessary for him to go over them again in the morning. A teacher likewise will arrange his course by distributing the lessons, not uniformly over the whole time which is at his disposal, but he reserves a part beforehand for one or several recapitulations."

A number of questions which have a bearing on economy of learning can be answered only apparently with reference to the image types.

First the question "whether it is easier to learn material which is heard than that which is read." The predominately 
visual type, it would seem, learns better by reading only, the auditory type by means of spoken words. Meumann (I3) reports of two of his subjects who retained predominately by means of acoustic images that they obtained better results when concentrating attention only upon these. Reading, in their case, exerted a disturbing influence, and when obliged to learn by reading only, attention being divided by the visual and acoustic images, they seemed to falter, for a time at least, between the two directions of attention. As a consequence learning became more difficult.

Closely connected with the former is the question: Is it more advantageous to learn aloud, half-aloud, silently or with repressed voice? Experimeats by Meumann and Pentschew (19) seem to indicate that, generally speaking, for adults balf-aloud learning is more favorable, for children silent learning or that with repressed voice. An explanation of the latter phenomenon is probably to be sought for in the fact that children oftener than adults belong to the predominately visual motor type.

Müller and Pilzecker (I6) found in the course of their experiments that certain letters by their quality or position in a syllable tend to attract attention in a greater degree than others; that the former are remembered while the latter are forgotten. Pathologists also relate cases of aphasia where only the first letter of a word, or the first few letters were remembered. Again, that in words reproduced by patients in a very mutilated form, the vowels only, and in their right order, vere frequently correctly repeated. ${ }^{1}$

Ziehen (25) observed that some individuals memorize the vowels quicker than the consonants, but that occasionally the reverse is the case.

These phenomena, again, must probably be explained by the difference of image types. Although not definitely established, it seems that consonants are better remembered by the visual type, vowels by the auditory type, while sounds presenting peculiar motor difficulties of pronunciation, in consequence of the longer time and greater stress which they require in learning, are apt to be better remembered by the motor type.

A further question of interest is the effect of rhythm upon learning. It can be briefly answered by saying that it is extremely unprofitable to learn without rhythm. Experiments tend to show that with some individuals the suppression of rhythmic speaking makes learning all but impossible. When continuously repeating a material we lapse involuntarily into a form of rhythmic speaking, and this is of advantage for learning. Whether one metre or the other is preferable we do not

${ }^{1}$ C. Moeli: Berliner. Klin. Wochenschrift, I89r. No. 49, p. 1167. 
know, some liking the trochee, others the iambic. There are reasons to suppose, however ( ${ }_{5}$ ), that as a rule that measure is most advantageous to the learner which in consequence of its frequent occurrence in the mother tongue is most familiar to him. Pentschew (I9), in experiments with German schoolchildren, on the other hand, found that with one exception the iambic (and not the trochee, as one might expect) was preferred.

Last, but not least in importance, is the influence which the rate of speaking or reading exerts upon learning. Experiments show that this greatly affects the despatch with which the learner reaches his goal. According to Ebbinghaus (7), the quickest possible rate is the most profitable. He found in learning lines of unconnected words and part of a poem, that a rate of 200 iambics per minute or 0.3 seconds for each measure is the most advantageous for him. $\mathrm{He}$ also found, when relearning the same lines 24 hours later, that those lines had been better retained which originally were learned with greater speed.

Quantz (20) reports as an incidental result of his experiments that usually those subjects remembered the most who in learning read most rapidly. Ogden (18), however, was unable to verify this result. In his opinion the number of repetitions increases with the greater speed, to such a degree that it makes learning in this way unproftable. Whitehead (24) advocates as a happy medium between rush and hurry on the one hand and drag and tedium on the other, a rate corresponding to the beating of the pulse, but he omits quantitatively to demonstrate that as the most favorable rate. Prof. Meumann (I3) holds that generally speaking neither the slow nor the rapid rate is the more profitable. "The one thing of importance," he writes, "is the adjustment of the rate of learning to familiarity with the material and to the progress of the memory work."

Thus opinions are well divided, and much can be said on either side of the question. Theoretically one would incline to the belief that firmness of association is apt to be enhanced by a growing rate of speed. For, without mentioning the well-known influence of time intervals upon strength of association, experiments on association in mediate succession also show that firmness of association diminishes correspondingly as the time-distance between its elements increases. On the other hand experiments on the forgetting of primary impressions have established the now well-known fact that recollection of these is most accurate not immediately after the sense stimulus has ceased, but about $\mathrm{I} / 2$ or 2 seconds later. Consciousness requires a certain time for working up an impression, and again the sense organ, the eye or ear, must regain its most favorable 
condition for receiving a second impression. Steffens (22), it will be remembered, observed that in learning sense material her subjects adopted instinctively a slower rate when endeavoring to memorize something more intensively. Again, Cattell, in experiments performed with a view to ascertain the rapidity of thought, found that although very familiar with German he takes $1 / 7$ second longer to name an object in that language than in English. He takes $1 / 4$ second to translate a word from German into English and $1 / 20$ second longer to translate in the reverse direction.

On consideration, then, Meumann's position seems well taken. When we approach unfamiliar material it is naturally disadvantageous to skim over it with eye and attention as rapidly as possible. In doing so we waste a number of repetitions upon were reception of optic-acoustic impressions, and some more in order to understand at all the content of what is to be learned. We get the best results by reading at first slowly and attentively, accelerating the rate later on. His experiments of learning lines of syllables from a rotating drum, the speed of which was controlled by the learner, show that the rate at first is very slow, much slower than when the rate was regulated by the experimenter. Then, with periodical fluctuations, the rate gradually increased until towards the end of learning it attained an enormons rapidity, which barely permitted hasty reading. This evidently proves that the rate of learning is adjusted to the progress in memorizing.

It is just as wrong, therefore, to read uniformly slowly as to read always as rapidly as possible. In following the former course, attention, as learning progresses, is not sufficiently occupied; it deviates; the learner becomes restless, impatient, and ill-humored, which cannot fail of exerting an unfavorable influence upon learning.

To recapitulate briefly, we have found that the principal points which represent the most favorable conditions of learning are as follows :

(I) Learning by means of "the whole method" for greatest accuracy and permanency of retention, or by means of a socalled "mediating method," as one which on the average is the most economical.

(2) Learning with adults accompanied by half-aloud speaking, with children by speaking in repressed voice, with visualizers by no speaking.

(3) Learning with rhythmic speaking.

(4) Learning which utilizes most fully those memory aids peculiar to an image type.

(5) Learning which in voluminous material judiciously distributes the repetitions. 
(6) Learning which adjusts the rate of reading and speaking to the progress of the memory work.

\section{MEMORY WORK IN THE SchoOL.}

The fact which more than any other impresses the student of memory experiments with school children is undoubtedly the great disparity between labor and gain which characterizes their memory work. Experiment not only has ascertained that pupils show a peculiar tendency to learu unecouomically, but that quantitatively, as well as qualitatively, their memory is but little developed, and naturally there arise the questions: (I) By what means can learning be put systematically upon a higher plane and (2) to what extent, and how most effectively can the school enlance the memory capacity of the child?

If nothing more, these experimental results have served to convince us that learning is not the relatively simple process it is ordinarily believed to be. Memory is a faculty infinitely complex. That of our neighbor's is not like ours. Indeed, it seems quite safe to assert that probably no two individuals have identically the same memory. For all that, it is the common practice of the school to demand of all pupils, without reference to mental preparation, the committing to memory of relatively difficult material, and to the unsuccessful the teacher's only advice is apt to be: "Try again." Thus to leave memorizing to the uncontrolled efforts, the planless, fumbling attempts of the child, means nothing less than inviting a waste of time and energy, and sometimes even courting total failure.

The first demand, therefore, to be made of the school, towards which the results of experimental investigations seem to point, is that of instruction in learning in accordance with psychological rules. That is to say, the activities of the pupil should be made to conform to what research has established as the conditions of economical learning. Such instruction could be theoretical and possibly also practical; the former consisting of acquainting the pupil gradually, as he grows older at greater detail, with the conditions and methods of economic learning, with particular reference to individual differences; the latter of systematic memory exercises in conjunction with the regular memory work of the school, but with practice for its own sake as the principal aim.

Should we attempt to answer the question, "how can this be done?" our present inadequate knowledge, of course, would preclude the possibility of establishing a set of hard and fast rules, and we must confine ourselves to tentative suggestions, some general directions which remain to be worked out in detail.

First, concerning theoretical instruction, two points would 
have to be touched upon. On the one hand, the pupil must be acquainted with those methods of learning whose employment generally is productive of the greatest advantage, and on the other, his attention must be called to the general memory aids and to the idiosyncrasies of the various types.

The teacher could ( $\mathrm{I}$ ) determine individually the characteristics of his pupils by examining a few each day.

(2) Call the attention of each pupil to his own characteristic way of learuing, and

(3) Show how to employ that method most advantageously, or pointing out its disadvantages, indicate how to improve it.

Such a demand, to be sure, presupposes on the part of the teacher an acquaintance with the methods by means of which the individual memory type of the pupil may be determined. These, however, need not at all be intricate. A simple proceeding like the following, for instance, may serve to give some preliminary information.

In order to determine whether a pupil retains better letters or numbers which he sees, or those which he hears, 25 letters or numbers divided into 5 lines of 5 each are arranged uniformly into a square, divided into 25 equal squares, and he is told to memprize these in the usual way from the left to the right. On being able to recite them without error, he is asked to recite those letters or numbers which from the left to the right form a diagonal line, or again, those contained within a vertical line of squares. Either one of these tasks would be relatively easy for the visualizer, who sees in his imagination a table such as has been shown him in reality. He will require for reciting these lines little more time than for the first. Not so the one who belongs to the auditory type. In his imagination exists no table which he can read. He hears an inner voice repeat to him the series of letters or numbers, but this is localized not in space, but in time. In order to find the second letter of the second line, for instance, it is necessary for him to count seven; in order to find the third of the third line he must count thirteen, and so on. All that, however, requires considerable time, much more time than for the visualizer who accomplishes such tasks quite rapidly and with relative ease.

A somewhat more complicated test, but one which is also more reliable, is the following: A number of phrases, words or syllables, sufficient to fill a certain given length of time, is presented first to the visual, next to the auditory memory, and it is then ascertained of which series the greater number has been retained. In the first series, for instance, during one hundred seconds, fifty words, one every two seconds, are exposed to the eye of the pupil, in a second series fifty words of a similar nature, one every two seconds, are spoken with a 
loud voice. If of the first series a pupil retains say 25 , of the second only is impressions, auditory memory has proved itself inferior to visual memory.

Care, however, should be taken not to place too much reliance upon a solitary test. Even under most favorable conditions the results of such rough tests are far from conclusive. And if we consider that various causes, such as general fatigue, or temporary fatigue of the eye or ear, interest in the meaning of words, defective attention, etc., greatly impair the accuracy of the values, it must be obvious that only repeated tests will enable us to determine with any degree of certainty the image type.

Having next ascertained the attention type of a pupil in regard to the previously developed fundamental differences, the teacher is now in a position to call the attention of the pupil to the peculiarities of his mode of learning, enlighten him in regard to its advantages or disadvantages, and instruct him how to improve it. According to Meumann's (13) observations, such tests and instruction are both interesting and useful.

The pupils by gaining a certain insight into the mechanism of learning get more enjoyment out of the formal act of learning. The teacher acquaints himself with the causes of the success or failure of their memory work. He discovers the particularly strong or weak points of individual pupils. He observes that the attention of the one adjusts itself with difficulty to the material or to the activity of learning, that of another with relative ease; that this pupil shows a tendency to memorize preferably by the aid of the sense elements, that one rather by paying attention to content; that "one" works with more perceptive representation of the material, "another" by apprehending logical connection. He notices that some learn by joining the parts to a whole, others by regarding each part only in its relation to the whole; that here, attention is characterized by intensity of concentration and fixating progression, there, by extension and fluctuation; that to one the acoustic elements offer the greatest aid, to others, the visual or motor elements or combinations of these.

In connection herewith, however, arises a mooted question among psychologists, namely, "whether it is better to encourage pupils to make use of as many memory aids as possible, or to work only with those which are best adapted to their own peculiar type." Experiments by Bigham, mentioned above, seem to speak for the former. Theoretically, also, one could argue: "The greater the number of associative connections, the more assistance for retention and reproduction."

Nevertheless, Meumann's experiments do not seem to bear this out. He found that individuals unskilled in learning suc- 
ceed better when working only with those aids to which they are accustomed. The unskilled of the acoustic type, for instance, retained better when the acoustic associations were not weakened by the subjects being told also to mind the visual images.

Furthermore, the fact that individuals unskilled in learning nonsense syllables, at first require an often quite ridiculously high number of repetitions, as much as 60 or 70 , for learning a line of 12 syllables, while on the following day only $1 / 2$ or $1 / 3$ of that number are required, and later on only as few as 2 or 3 repetitions, also seems to indicate that the learner at first, hesitating between various modes of learning, wastes the greater part of his efforts, that he succeeds better after having found those memory aids which are best adapted to his own peculiar type, and lastly, that it is the skilled learner only who is able to use profitably aids uncommon to his type.

Hence, Meumann's proposition that at first children should be taught how to use properly their innate memory aids, and only when more skilled should they attempt to enhance their memory performance by gradually remedying the deficiencies of their mnemonic faculty.

A second point at issue is the question "how do rational and mechanical memorizing cooperate?"

The school rightfully insists that the former is to be preferred.

Our memory, we know, does not retain a multitude of impressions seen and heard hundreds of times. This proves that it is not repetition as such which is responsible for learning and retaining, and which makes free reproduction possible, but that, as a rule, we remember only what we have apprehended with attention and with intention of retaining.

Repetitions, then, however necessary for retention, make reproduction most sure only when they are consciously and intentionally for the purpose of acquisition. On the other hand it might be asked, "Is there such a thing as purely rational memorizing, which can dispense with all mechanical elements of mere reciting, and is that the ideal way of learning for children?

Psychological experiments show that for trustiness and permanensy of retention, mere apprehension of content does not suffice, and that for permanent acquisition the mechanical element of mere repetition must co-operate. Repetitions, in fact, have the same effect for sense and non-sense material, although for the former a much smaller number is required. Side by side with attention and understanding of content, they have a peculiar independent effect on learning.

Wherever in experiments psychophysical condition, or some cause or the other, prevents a thorough concentration of atten- 
tion, and the attempt is made to remedy that defect by multiplying the number of repetitions, it has been found, as our investigation of learning by "the whole method" clearly showed, that just such materials are remembered longest and leave the most persisting traces in memory. And again where, as it sometimes happens, verse-metre or content being particularly stimulating, attention is intensified, and a pleasurable emotional tone induced, in consequence of which a saving in repetitions occurs, it has been ascertained that retention of this kind of material is not as permanent. For anything, therefore, to become a permanent possession of the mind repetitions are necessary.

Moreover, especially in verbatim memorizing, it would seem, these repetitions must contain a mere mechanical element. The mere retention of ideas or association of ideas does not enable us to recite a poew. It must be supplemented by association of the optic-acoustic-motor elements of the heard and spoken words, which, though secondary in importance, are not a negligible factor in learning. While, therefore, apprehension of content and constant direction of attention upon logical connection should be accentuated, and the pupil, perhaps more than ever before, be guarded from substituting for these the mindkilling. "mechanical" learning of a text, we must ask of the teacher, as another point for theoretical instruction, to advise pupils how to effect cooperation of sensible content with the indispensable mechanical part of learning.

The objects of instruction then, according to their importance, are to be placed in somewhat like the following order:

(I) Attention upon content.

(2) The advantages or disadvantages of the various methods of learning.

(3) The claracteristics of the image type to which the learner belongs; the fundamental characteristics of his attention, and the disadvantage of its slow adaptation.

(4) Cooperation of rational and mechanical memorizing.

In advocating the introduction in the school of systematic memory exercises, we meet a number of serious difficulties. In the first place we are apt to encounter the "laisser faire" theorist, who will say: Is not the pupil daily, yes hourly, engaged in exercises with the ultimate object in view of strengthening memory?

This, of course, we cannot deny; but we simply contend that the way in which it is done, is not as effective as it might be. If the method which is usually followed in the schools is a good one, we ought to be able to prove that the memory of those pupils who have followed it longest is much superior to that of 
beginners, that is to say, the memory ability of older pupils should be considerably greater than that of younger ones, and the average memory capacity of the higher classes should greatly surpass that of the lower ones.

But is that the case?

In order to answer, let us note the results of experiments made for the purpose of quantitative measurement of the memory performance of school children.

Binet and Henri (2) examined the memory of 380 pupils of primary schools in Paris, ranging in age from 8 to 13 years, in the following manner: Seven words in succession at a rate of one for every half a second were pronounced, and the subjects were asked to repeat immediately as many as they could remember. The number correctly remembered having been noted, another series of seven words was pronounced for the same purpose, and this proceeding was repeated 7 times in all.

The immediate memory was measured by counting all the words correctly reproduced and by dividing this number by 49, while permanent retention was determined by asking the subjects to reproduce all words which they remembered of the total series.

It was found that the number of words immediately remembered varied with age, but that this variation, for stibjects of from 7 to 12 years, was remarkably small, being only $3 /$ ro for a line of 7 words. The average number of words remembered was 4.7 correct out of a possible 7 . The average number remembered in the 4 th class (approximately 8-year-olds) was 4.6 ; 3 d class, 4.9 ; 2 d class, 4.8 ; Ist class, the oldest pupils, 4.9.

Still more discouraging are the results of experiments by $B$. Bourdon (4) who examined, from a strictly pedagogical point of view, "the influence of age upon immediate memory." About roo lyceum pupils, ranging in age from 8 to 20 years, were individually examined, and this is the author's conclusion: The immediate memory remains almost stationary from the Sth until the 2oth year. He proposes, however, to distinguish two periods: one, from 8 to I 3 years inclusively, during which a slight growth was noticed; the second, from 14 to 20 years, during which no perceptible improvement was found.

Experiments by Bolton and by Jacobs, an English psychologist, on the whole have verified the above results.

We can no longer doubt, then, that generally speaking, development of memory during school life is exceedingly small. Moreover, could one not justly raise a question, how much the training of the school contributes to what little improvement there is, knowing, as we do, that the mere fact of advancing age (at least within certain limits) naturally increases mne- 
monic proficiency? If the general psychological and biological assumptions are correct, "that childhood and youth constitute the golden period for laying the foundations of a good memory, because then the neural substance is most plastic," could one not, on the strength of the above figures, come to the conclusion that the present methods of the school are radically wrong, and its efforts woefully misdirected?

Amazing as such assertions may seem, and exaggerated as they doubtless are, nevertheless the experimentally established fact that the immediate memory of adults who years ago have left the school and since then had no occasion to practice memorizing surpasses that of any child, must lead one to think that they are not entirely without a certain element of truth.

A second series of objections against systematic memory exercises grows out of the question: "Is it possible to improve memory and to what extent can this be accomplished ?"' Certain psychologists, it will be remembered, hold that no amount of culture is capable of modifying general retentiveness, and that all improvement of memory lies in the line of elaborating the associates of each of the several things to be remembered. A man's general retentiveness is a physiological quality, given once for all with his organization, and which he can never hope to change. While they admit that whatever amount of intellectual exercise is bracing to the general tone and nutrition of the brain, will also be profitable to the general retentiveness, they maintain that more than this we cannot say. Accordingly the popular notion that certain exercises systematically repeated will strengthen not only a man's remembrance of the particular facts used in the exercises, but his general faculty of remembering, must be erroneous.

When school boys improve by practice in ease of learning by heart, such improvement will, they are disposed to think, be always found to reside in the mode of study of the particular piece, due to the greater interest, the greater suggestiveness, the generic similarity with other pieces, the more sustained attention, etc., and not at all to any enhancement of the brute retent!ve power.

Another argument against general memory exercises is somewhat as follows : According to the modern psychological conception of the nature of consciousness, we must distinguish between various special memories. Will exercise of one of these, it is asked, be instrumental in improving other special memories of a given individual? May a composer, for instance, hope to improve his visual memory by strengthening, by means of systematic practice, his acoustic memory? Experiments, it is explained, do not justify us in answering that question in the 
affirmative. All we know is that practice in retaining certain impressions aids memory of that particular kind. Even though it may appear that exercising a certain special memory at the same time improves other memory forms, it is probable that such an improvement does not rest upon the exercise of general memory function, but rather upon the incidental acquisition of certain "schematic knacks," a more suitable general conduct, which facilitates learning. In brief, existence of a general memory function is denied, from which follows that general memory exercises are out of the question.

The answer to such objections is, that even though the results of systematic memory exercises were but the acquirement of a more suitable, a more correct conduct on the part of the learner, his efforts would not be entirely lost. For practical pedagogy it is of secondary importance, whether the coexercise of other special memories rests upon one cause or another, upon the existence of a general memory function which is developed, or upon the enhancement of other factors, like attention, interest, etc. It is interested chiefly in the question whether or not a general memory exercise is possible, whether formal memory exercises tend to enhance the memory performance of the child, and only incidentally in the psychological ground upon which such an improvement may rest.

Unfortunately, however, even these questions, for the present at least, cannot be answered with any degree of certainty. About the only experiments to be reported which record a positive result, are some by Ebert and Meumann (8), and these, as Meumann himself acknowledges, are open to certain criticisms, which, though each one in itself may seem insignificant, taken altogether cannot fail of rendering the results less definite than is to be desired. Ebert and Meumann's investigations aimed at a purely objective answer to the question, "whether a general enhancement of memory occurs when one special memory is improved by exercise." Briefly stated, their experiment was as follows : First of all, in a preparatory series of experiments the present ability of all subjects was measured, in regard to immediate as well as to permanent retention. What may be termed "a cross-section"' was made through as many special memories as seemed necessary to determine the effect of purely one-sided mechanical exercise upon memory as a whole. Measurement of immediate retention was in regard to (a) nonsense material, comprising letters, numbers and nonsense syllables, (b) sense material, such as logically disconnected words, (c) Italian vocabulary, (d) verses of a poem, and (e) sentences in prose. Permanent retention was measured in regard to (a) lines of nonsense syllables of various lengths, and lines of optical signs, (b) Italian vocabulary, verses of a poem and sentences 
in prose. Next these subjects exercised for 36 consecutive days but one special memory form, that of mechanical memorizing of nonsense syllables, when again a cross-section of the previously mentioned special memories was made in order to determine the effect. Having ascertained an improvement, mechanical memory exercise was resumed by some for I 8 days, by others for 36 days, and, finally again, all special memories of the subjects were quantitatively examined.

The following are the figures obtained :

Average immediate retention

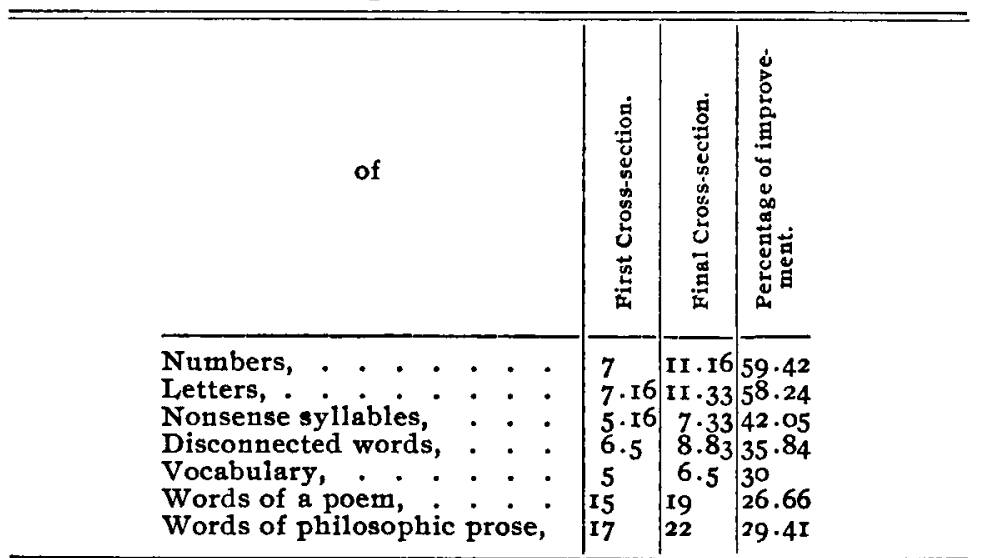

Permanent Retention. Average number of repetitions necessary

\begin{tabular}{|c|c|c|c|c|}
\hline for & & 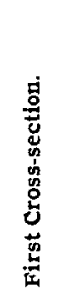 & 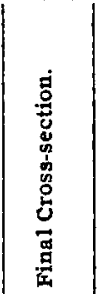 & 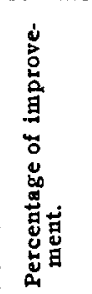 \\
\hline $\begin{array}{l}\text { One nonsense syllable, } \\
\text { One optical sign, } \\
\text { One vocable, } . . \\
\text { One line of a poem, } \\
\text { One printed line of philo- } \\
\text { sophical prose, } \\
.\end{array}$ & $\begin{array}{l}\text { First learning, } \\
\text { Relearning } 24 \\
\text { hours later, } \\
\text { First learning, } \\
\text { Relearning, } \\
\text { First learning, } \\
\text { Relearning, } \\
\text { First learning, } \\
\text { Relearning, } \\
\text { First learning, } \\
\text { Relearning, }\end{array}$ & $\begin{array}{l}2.1 \mathrm{I} \\
0.49 \\
3.83 \\
0.68 \\
0.273 \\
0.056 \\
0.75 \\
0.14 \\
1.45 \\
0.3\end{array}$ & $\begin{array}{l}0.48 \\
0.20 \\
0.90 \\
0.30 \\
0.108 \\
0.036 \\
0.47 \\
0.07 \\
0.5 \\
10.09\end{array}$ & $\begin{array}{l}77 \cdot 25 \\
59 \cdot 18 \\
76 \cdot 5 \\
55 \cdot 88 \\
60.43 \\
35 \cdot 71 \\
37 \cdot 33 \\
50.0 \\
65 \cdot 51 \\
70.0\end{array}$ \\
\hline
\end{tabular}


The results of Ebert and Meumann's experiments show, (I) that the one-sided exercise of one special memory at the same time improved the ability of learning and retaining other memory material of an entirely different nature; or differently expressed, the exercise of one special memory resulted in the co-exercise of other special memories; and (2) that this coexercise does not occur in a uniform way, but that other special memories are enhanced at a ratio which is determined by their relation in regard to the nature of the material and mode of learning to the special memory exercised.

As to the extent to which menory can be trained, two points must be considered : (I) How far is it possible to enhance memory ability?

(2) How far is it possible to adjust onesidedness of imaging and idiosyncrasies of memory?

Meumann's experiments justify, as he thinks, the conclusion that "the possibilities in improving memory are practically unlimited," that is to say, a given memory ability, through exercise, can be maximally developed. Two individuals who at first required 14 and 49 repetitions for learning a line of 12 syllables, learned finally with 3 , sometimes with only 2 repetitions, and he expresses the conviction that sufficient practice will lead to the ability of learning such a line after hearing or reading it but once.

With 3 individuals, 36,40 , and 54 years of age, the effect of exercise, although considerable, was less than that of younger persons. At about the 4oth year of life it seems, in spite of maximal exercise, a certain deterioration of memory can be noticed. The time of life at which memory ability is at its best, as is borne out by experiments with individuals of from 7 to 54 years of age, is that between 20 and 25 . As to point 2, real defects of memory, where total inability of memory for certain elements (a lack of acoustic memory for tones, for instance) exists, cannot be much improved by exercise.

Wherever, on the other hand, a mere predominance of certain sense elements is found, equalization of such individual onesidedness to a certain extent seems possible by continued exercise.

Of the criticisms of these experiments the following may be mentioned :

(I) It may be held that the improvement is due in part to practice in all-around imaging.

(2) It may be said that not only practice in learning nonsense syllables, but the practice obtained in the different tests, learning other material, contributed to the results, and that in determining the present ability for memorizing the different material, not a cross-section, but rather a diagonal cut was made. 
(3) It may be objected that the mechanical learning of nonsense syllables does not really constitute exercise of a special memory; that in practicing mechanical memorizing we perfect by practice an element which is coefficient in all learning -a general elementary condition of learning.

As stated before, however, such objections are valid only from the view point of psychology, while for pedagogy the possibility of a general memory exercise may be said to have been established. Still the question arises whether on the strength of a solitary experiment, conducted under conditions differing from those which obtain where it is to be applied, we should make such a far-reaching demand of the school as that of formal memory exercises? And granting that: is there time for such exercises in our already over-burdened schools? Are we justified in asking a development of memory at the cost of other mental faculties?

Moreover, two further considerations, one psychological, the other practical, seem to speak against the introduction of formal memory exercises in the school.

There is, on the one hand, the danger, by choosing nonsense material as the means of exercising memory, of overemphasizing the mere mechanical element of learning, and on the other, the general difficulty of preparing material which would not defeat its own aim.

Let me review in part an outline for such memory exercises, as submitted by Van Biervliet (23), a French psychologist, in order to illustrate what I mean.

"It is unnecessary to show," he writes, "that a sensation, an emotion, an image. remains more profoundly engraved in memory the more vivid the impression by which it was produced. Fortifying the impressions, therefore, means fortifying our memories. We retain that which we have seen, but we retain infinitely better that which we have looked at; we recollect a conversation which we have heard, but we recollect much better a statement we have listened to; we recall that which we have spoken in a natural voice, but much better that which we have solemuly declared."

From this he concludes, that in order to fortify the visual memory we must teach one to look at things; to improve auditory memory, teach one to listen; to strengthen motor memory, teach one to articulate.

For visual memory this may be accomplished by concentration of attention upon, and the exact reproduction of, objects presented. Beginning with simple objects, such as lines of different length, squares and objects of three dimensions, they should gradually become more complex until, finally, shaded forms are exposed to the eye for a few seconds. These the 
pupils should be asked to reproduce with pencil from memory -as exactly as possible.

For auditory and motor memory the exercise should consist in pronunciation of series of syllables differing in length and in the nature of their formation. They should be made up so as to prevent as much as possible assistance from rational memory.

First, one might propose syllables in which the vowels only differ, such as lalolilalulilo, bibabobubibabobibo. Next, series where the vowel remains the same and the consonants only vary, as lafabarakalamana. Such can be conveniently taken from Sanscrit. Finally, series of syllables in which both the vowels and the consonants differ, as labafigamoru, etc, etc.

Although Van Biervliet's essay is full of important points and valuable suggestions, the shortcomings of his plan for memory exercises are so obvious as to make it unnecessary to elaborate upon them here. If one recalls to mind the ortographic exercises of the so-called Philanthropinists and the long ago abandoned so-called "articulation exercises" of Pestalozzi, it can hardly be expected that this part of his plan will meet with serious consideration.

On the whole, then, it seems not too much to say that the time is not ripe for the adoption of formal memory exercises as a part of the curriculum of the school. What, however, can be advocated with perfect safety is the previously developed theoretical instruction in economical memorizing, a perfection of methods of learning, and above all exercise in economical memorizing in connection with the regular work of the school, by strictly following psychological rules. The needs of these, it seems to me, cannot be too strongly emphasized. Nor do I wish to question the possible advantage of formal memory exercises in particular individual cases. What is insisted upon, however, is that their general usefulness be unquestionably established and that a complete organization of such exercises be based on the combined results of psychological experiment and of practical pedagogy before assigning them as a part of the regular work of the school.

In closing, a brief résumé of the points of practical value for the school may be added:

(I) The urgent need of employing economical methods of learning, which can be met by acquainting the pupils with the value of the various methods of learning and by employing them in connection with the memory work in the school.

(2) The importance of taking into account individual differences, - the idiosyncrasies of the learning types and of the image types; the necessity of calling a child's attention to the peculi rities of its way of learning, of showing him how to utilize most fully innate memory aids and how to improve upon 
them. Out of the former grows the practical problem of the manner of presenting material in the school.

(3) Consideration of the relatively inferior memory capacity of children, which suggests that the memory performance required should be in proportion to the average age of the class.

(4) The factor of fatigue in learning, as bearing upon the behavior of attention; the need of pauses between repetitions wherever a great number is required,-a point which touches upon the practical problem of recess between recitations.

(5) The importance of correct formation of associations and the inhibitory influence of irrelevant associations. A much favored method of teachers is to induce a pupil, by questioning, to find a correct answer for himself. By this method wrong associations are easily formed.

Another reprehensible habit of teachers is that of misleading the pupil by the form in which the question is put. Every wrong answer tends to inhibit recollection of the right one, and questions should be put so as to suggest as nearly as possible a correct one. Correct answers are obtained easier when the same answer fits several questions, wrong answers, when several replies fit the same question.

(6) The economical value of several secondary memory aids, of which the most important are the judicious distribution of repetitions in learning voluminous material, and "the adjustment of the rate of learning to the progress of the memory work."

\section{BIBLIOGRAPHY.}

I. BINET, A. Psychologie des grands calculateurs et joueurs d'échecs. Hachette, Paris, I894. $364 \mathrm{p}$.

2. BiNET, A. ET HENRI V. La mémoire des mots et des phrases. L'Annee Psychologique, 1894, Vol. r, pp. I-59.

3. Borton, T. L. Growth of memory in school children. $A m$. Jour. of Psy., A pril, I892, Vol. 4, pp. 362-380.

4. Bourdon, B. L'infuence de l'âge sur la mémoire immédiate. Rev. Philosophique, 1894 , Vol. 38, pp. I48-167.

5. Borरham, w. H. Retroactive amnesia. Am. Jour. of Psy., July-Oct., rgo3, Vol. I4, pp. I18-I32.

6. Danieis, A. H. The memory after-image and attention. $\mathrm{Am}$. Jour. of Psy., Jan., 1895, Vol. 6, pp. 558-564.

7. EbBiNGhaUs, $H$. Uber das Gedächtnis. Leipzig, $1885.169 \mathrm{p}$.

8. EBERT, E. UND MEUMANN, E. Uber einige Grundfragen der Psychologie der Ubungsphänomene im Bereiche des Gedächtnisses. Samml. von Abhandl. zur psy. Päd., Ig04, Vol. I, pp. 437-668.

9. EPHRUSSI, P. Experimentelle Beiträge zur Lehre vom Gedächtnis. Zeits. f. Psy. und Physiol. der Sinnesorgane, I904, Vol. 37 , pp. 56-103, 16I-234.

Io. FINZI, J. Zur Untersuchung der Auffassungsfähigkeit und Merkfähigkeit. Kräpelin's Psy. Arbeiten, I9oI, Vol. 3, pp. 289-384. 
II. JosT, A. Die Assoziationsfestigkeit in ihrer Abhängigkeit von der Verteilung der Wiederbolungen. Zeits. f. Psy. u. Physiol. d. Sinnesorgane, I 897, Vol. I4, pp. $436-47^{2}$.

12. LIPMANN, O. Die Wirkung der einzelnen Wiederholungen auf verschieden starke und verschieden alte Assoziationen. Zeits. f. Psy. u. Physiol. d. Sinnesorgane, 1904, Vol. 35, pp. 195-233.

13. MeumanN, E. Uber Okonomie und Technik des Lernens. Die Deutsche Schule, I903, Vol. 7, Pp. I33-155, 205-225, 284-299, $354-368,425-450$.

14. MÜNSTERBERG, H. Beiträge zur experimentellen Psychologie. No. I-4. Freiburg, I889-92.

14 a. BIGHAM, J. Memory. Psy. Rev., I894, Vol. I, pp. 453-46r.

15. MÜLLER, G. E., and SchUMANN, F. Experimentelle Beiträge zur Untersuchung des Gedächtnisses. Zeits. f. Psy. u. Physiol. d. Sinnesorgane, I894, Vol. 6, pp. 8I-I9o, 257-339.

16. MÜLLER, G. E., UND PILZECKER, A. Zur Lehre vom Gedächtnis. Zeits. f. Psy. u. Physiol. d. Sinnesorgane, I900, Ergänzungsband, Vol. $I$.

17. NetschajEFF, A. Experimentelle Untersuchungen über die Gedächtnisentwickelung bei Schulkindern. Zeits. f. Psy. u. Physiol. d. Sinnesorgane, I900, Vol. 24, pp. 32I-35I.

- _- Uber Memorieren. Samml. von Abhandl. a. d. Gebiete d. päd. Psy. u. Physiol., I902, Vol. 5, No. 5, pp. 29.3-329.

18. OGDEN, R. M. Untersuchungen ïber den Einfluss der Geschwindigkeit des lauten Lesens auf das Erlernen und Behalten von sinnlosen und sinnvollen Stoffen. Arch. f. d. ges. Psy., I903, Vo1. 2, pp. 93-I89.

I9. Pentschew, $C$. Untersuchungen zur Okonomie und Technik des Lernens. Arch. f. d. ges. Psy., 1903, Vol. I, pp. 417-526.

20. Quantz, J. O. Problems in the psychology of reading. Psy. Rev. Mon. Supp., No. \$, 1897, Vol. 2, 51 p.

2I. SmITH, W. G. The relation of attention to memory. Mind, Jan., I895, N. S., Vol. 4, pp. 47-73.

22. STEFFENS, LotTIE. Experimentelle Beiträge zur Lehre vom ökonomischen Lernen. Zeits. f. Psy. u. Physiol. d. Sinnesorgane, I900, Vol. 22, pp. 321-382.

23. Van BIfRVLIRT, J. J. Esquisse d'une éducation de la mémoire. Revue de Philosophie, I902-03, Vol. 3, pp. II 7-I37, 479-516.

24. WhITEHEAD, L. G. A study of visual and aural memory. Psy. Rev., I896, Vol. 3, pp. 258-269.

z5. ZIEHEN, TH. Leitfaden der Physiologischen Psychologie in I5 Vorlesungen. Gustav Fischer, Jena, 1906, 280 p. See p. 217. 